\title{
Preoperative and intraoperative variables to predict mortality: Which comes first, the chicken or the egg?
}

\author{
Umberto Benedetto, MD, PhD, and Gianni D. Angelini, MD
}

From the Bristol Heart Institute, University of Bristol, School of Clinical Sciences, Bristol, United Kingdom.
Disclosures: Authors have nothing to disclose with regard to commercial support.
Received for publication Nov 10, 2016; accepted for publication Nov 10, 2016; available ahead of print Dec 17,
2016.
Address for reprints: Umberto Benedetto, MD, PhD, Bristol Heart Institute, University of Bristol, Upper Maudlin
St, Bristol BS2 8HW, United Kingdom (E-mail: umberto.benedetto@ bristol.ac.uk).
J Thorac Cardiovasc Surg 2017;153:1126-7
0022-5223/\$36.00
Crown Copyright @ 2016 Published by Elsevier Inc. on behalf of The American Association for Thoracic Surgery
http://dx.doi.org/10.1016/j.jtcvs.2016.11.018

In their article in this issue of the Journal, Lamarche and coworkers $^{1}$ present a retrospective study designed to improve mortality prediction at intensive care unit admission by including 7 factors that can occur intraoperatively: (1) the need for an intra-aortic balloon pump; (2) ventricular assist device, or extracorporeal membrane oxygenation on leaving the operating room; (3) the presence of any intraoperative complication reported by the surgeon; (4) the use of inotropes; (5) the use of high-dose vasopressors; (6) red blood cell transfusion; and (7) cardiopulmonary bypass (CPB) time. Lamarche and coworkers ${ }^{1}$ are to be congratulated for their attempt to estimate the impact of intraoperative factors in determining mortality after cardiac surgery; however, several aspects limit the utility of their risk model.

First, intraoperative factors such as the need for inotropes, use of high-dose vasopressors, intra-aortic balloon pump support, and mechanical circulatory support with extracorporeal membrane oxygenation and ventricular assist devices are all strongly associated with poor baseline left ventricular systolic function, which was not included in the model of Lamarche and coworkers. ${ }^{1}$ Moreover, these variables are highly correlated. For instance, patients requiring intraoperative intra-aortic balloon pump or ventricular assist device support are likely to receive inotropes and high-dose vasopressors. In addition, one might argue that prolonged CPB time is associated with more complex operations, such as multiple valve and combined procedures, which were already included among preoperative risk factors. In statistics, the condition of very high intercorrelations or interassociations among the independent variables is known as multicollinearity and affects calculations regarding individual predictors. Because multicollinearity causes imprecise estimates of coefficient values, the resulting out-of-sample predictions will also be imprecise. $^{2}$ The problem of multicollinearity in risk modeling is well recognized in cardiac surgery, and scores designed with the "law of parsimony" in variable selection have been shown to provide better accuracy and calibration than seen with more complex risk scores.

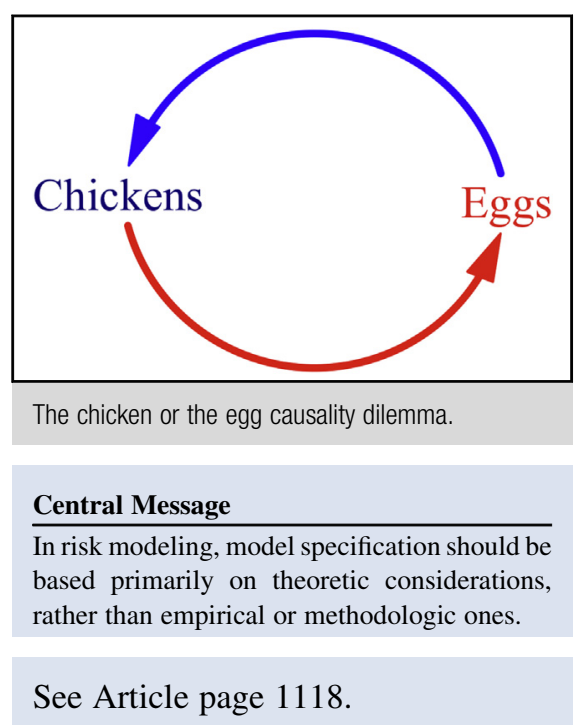

With regard to intraoperative complications, Lamarche and coworkers ${ }^{1}$ provided a vague definition (any intraoperative complication reported by the surgeon) that does not clarify the level of clinical relevance required for intraoperative complications to have an impact on mortality. For instance, coagulopathy includes a very wide spectrum of conditions, including the effect of preoperative aspirin administration, which has been consistently demonstrated to not affect operative mortality. ${ }^{4}$

Finally, it should be noted that CPB time was retained as a risk factor in their model (for a 1-hour increase), with CPB time considered to be 0 for off-pump procedures. On the basis of this definition, we might conclude that off-pump coronary bypass surgery is associated with a lower mortality than on-pump coronary bypass surgery requiring 2 hours of $\mathrm{CPB}$, and this conclusion goes against all the evidence. ${ }^{5}$ It is intuitively apparent that CPB time is mainly determined by the complexity of the procedures, and there is a nonlinear correlation between CPB time and mortality.

Going back to the original question, "Which comes first, the chicken or the egg?" we can conclude that intraoperative variables included in the model of Lamarche and coworkers ${ }^{1}$ were highly determined by baseline conditions. Model specification, which refers to the determination of which independent variables should be included in or excluded from a regression equation, is the first and most important step in risk modelling. Model specification should be based primarily on 
theoretic considerations, rather than empirical or methodologic ones.

\section{References}

1. Lamarche Y, Elmi-Sarabi M, Ding L, Abel JG, Sirounis D, Denault AY. A score to estimate 30-day mortality after intensive care admission following cardiac surgery. J Thorac Cardiovasc Surg. 2017; 153:1118-25.e4.

2. York R. Residualization is not the answer: rethinking how to address multicollinearity. Soc Sci Res. 2012;41:1379-86.
3. Ranucci M, Castelvecchio S, Menicanti L, Frigiola A, Pelissero G. Risk of assessing mortality risk in elective cardiac operations: age, creatinine, ejection fraction, and the law of parsimony. Circulation. 2009;119:3053-61.

4. Sun JC, Whitlock R, Cheng J, Eikelboom JW, Thabane L, Crowther MA, et al. The effect of pre-operative aspirin on bleeding, transfusion, myocardial infarction, and mortality in coronary artery bypass surgery: a systematic review of randomized and observational studies. Eur Heart J. 2008;29:1057-71.

5. Lamy A, Devereaux PJ, Prabhakaran D, Taggart DP, Hu S, Paolasso E, et al; CORONARY Investigators. Effects of off-pump and on-pump coronary-artery bypass grafting at 1 year. N Engl J Med. 2013;368:1179-88. 